\title{
Role of Indian Science Congress Association, 1914-1947
}

\author{
Sneha Sinha* \\ (Received 14 May 2018; revised 19 May 2018)
}

\begin{abstract}
The paper identifies Indian Science Congress Association (ISCA) as a crucial organization in shaping science in India. As early as 1914, it was the only platform that provided scope for interaction between scientific workers from varied disciplines of science annually. Based on the model of British Association for Advancement of Science (BAAS), it fostered advancement of various scientific disciplines and also enabled coordination between disciplines. ISCA played a critical role in foundation of scientific societies, academies of science, specialized institutions and initiation of scientific journals during 19141947. ISCA developed community consciousness among Indian scientists and also formed a medium for greater interaction between not just Indian scientists but also European scientists in India as well as delegates from abroad. It was a forum for younger scientists to present their research and provided them scope for interacting with senior scientists. The sectional committees of ISCA ensured a peer-reviewed system. It emerged to be a platform for greater recognition of social obligation of science. The paper primarily analyses ISCA's role in institutionalization and professionalization of science in pre-Independence era. During the period of study, ISCA formed the core of numerous scientific activities in India and saw greater international recognition and interaction with the political leadership within India as well.
\end{abstract}

Key words: Indian Science Congress Association, Indian Science Congress, Science in PreIndependence Era, Indian Science.

\section{INTRODUCTION}

The emergence of modern Science \& Technology (S\&T) in India has been an important field of research for social historians of science. They focus on understanding the nature of emergence of modern S\&T and its colonial context (Raj, 2007; Kumar, 2006; Chakrabarti, 2004; Baber, 1998; Krishna eds., 1997, pp. 236-281 and Sangwan, 1991). The colonial science policies were not aimed towards popularization or professionalization of science in India. There is no focused research on scientific institutions which are critical for shaping S\&T in a country. The professional associations like BAAS, AAAS (American Association for Advancement of Science), ANZAAS (Australian and New Zealand Association for the Advancement of Science), etc.
(Howarth, 1931; Kohlstedt, 1976; MacLeod, 1988) have been adequately studied. Although ISCA has been identified as an important scientific organization (Krishna et al., 1997, p. 243), a focused research is lacking. The paper analyses ISCA's role in shaping science in India during 1914 and 1947.

\section{BACKGROUND TO ISCA}

During eighteenth and nineteenth century, scientific services and societies were primarily European enclaves, not aimed towards cultivation and popularization of science in India. The Asiatick Society of Bengal (ASB) was the first step towards institutionalization of science in India. Initially, it had no rules pertaining to enrolment of Indians as members (Asiatic Society

\footnotetext{
* Ph.D. research scholar, Centre for Studies in Science Policy, Jawaharlal Nehru University, New Delhi-110067, India; Email: snehasinha307@gmail.com
} 
of Bengal, 1885, p. 8). Its publications also attest to greater participation by Europeans than Indians especially in the natural sciences section (Education, Part A, August 1899, No. 58). Later, numerous scientific societies emerged but gave very limited or no scope for popularization of science among Indians who were merely treated as subordinates. They were mostly regional and discipline-centric ${ }^{1}$.

From mid-nineteenth century, increased efforts were made by Indian intelligentsia towards popularization of science. Mahendralal Sircar established Indian Association for Cultivation of Science (IACS) in 1975 which can be viewed as the first concrete and organized step in this direction. However, because of lack of funds it couldn't fulfill its objectives during its founder's lifetime (IACS, 1976). This formed the context for foundation of ISCA in 1914 by John Lione Simonsen and P S MacMahon who were concerned about the appalling state of scientific teaching and research in India. Although the proposal met with general consensus, concerns were raised about the practicability and time ripe for an institution modeled on BAAS in India (ISCA, 2003, pp. 220-223).

\section{Institutionalization of Science}

Scientists associated with ISCA played a critical role in founding numerous departments, discipline-centric courses, specialized institutions and national laboratories catering to different specialisms of science. Prior to the Second World War there was little or no attention towards coordination between scientific and industrial research. The Second World War brought to light the unorganized state of scientific and industrial research in India. The urgent need was voiced by J C Ghosh at the Lahore session of ISCA in 1939 and later by $M$ Visvesvaraya in his address at Indian Institute of Science, Bangalore (ISCA,
1939). As a result, CSIR was established in 1942. S S Bhatnagar persuaded the government for establishing national research laboratories during 1940s.

\section{Professionalization of Science}

The scientific institutions, associations, societies, etc. are essential for cultivation and advancement of science. Krishna opined that ISCA played an instrumental role in organization of scientific societies, academies of science, etc. between 1914 and 1947 (Krishna, 1997, pp. 236245). ISCA has acted as a platform for proposing and discussing the organization and evolution of various professional scientific bodies. The scientists associated with ISCA have contributed immensely towards foundation of scientific societies, academies of science and scientific journals during the period. It certainly provided an environment conducive for their growth. ISCA provided platform for advancement of scientific disciplines and through its joint meetings enabled greater coordination between sciences, in order to cater to the general problems facing the country and in realising the social obligation of science. The steady increase in ISCA's membership and papers presented is a clear indicator of professional-ization. ISCA's sectional meetings provided scope for peer-review system. The period under study saw knowledge production in numerous sciences and greater international recognition of Indian scientists.

\subsection{Scientific Societies, Academies of Science and Scientific Journals}

The sectional committees of ISCA enabled greater intercourse between scientific workers of similar fields which fostered their organization and led to the foundation of numerous scientific societies. After 1920, total number of thirty-two learned scientific societies, academies of science

\footnotetext{
1 These include Literary and Scientific Society, Madras; Agricultural and Horticultural Society of India; Calcutta Medical and Physical Society; Agriculture and Horticulture Society of Punjab; Bombay Natural History Society.
} 
and professional associations came up until India's Independence (ISCA Proceedings, 1914-1947). ISCA and its members played a critical role in the foundation of Indian Botanical Society, Indian Psychological Association, Indian Chemical Society, Indian Physical Society, etc. Certainly, ISCA provided a conducive eco-system and stimulated the proliferation of numerous scientific societies and associations. During ISCA sessions need for academies of science were voiced and as a result of efforts of scientists associated with ISCA, regional and national science academies like United Provinces Academy of Science, National Institute of Sciences of India and Academy of Science in Bangalore came up (ISCA, 2003, pp. 328). NISI was formally inaugurated by Fermor during ISCA session in 1935 (NISI, 1935). Prior to twentieth century, scientific journals were practically non-existent and most of the researches done in India were published in journals abroad (Krishna et. al., 1997). During this period, discipline-centric journals associated with scientific societies and academies of science came up. As a result of demands raised during ISCA session for a journal similar to 'Nature' in Britain, Current Science came up and ISCA played a critical role in its inception (ISCA, 1932). The scientists associated with ISCA like P C Ray and Meghnad Saha were critical in the foundation of the Indian Science News Association and publication of the journal, Science and Culture.

\subsection{Membership of ISCA}

At the time of the inception of ISCA, Indians among the scientific workforce of the country were limited and were largely scattered and isolated in specific parts of the country. The President of the Mathematics and Physics section of the fourth Congress, D Mackichan noted that the number of Indian workers participating in the Congress had increased and it represented a science Renaissance in India (ASB, 1917, p. cixii). During 1914 and 1947, there is a marked increase in the membership of ISCA especially of the Indian scientists and papers contributed by them. The founder president of ISCA, Asutosh Mookerjee was an Indian and during 1914 and 1947, there were fifteen British and nineteen Indian General Presidents. An analysis of ISCA's proceedings attest to presence of noted scientists as members, general presidents, sectional presidents and as members of executive council. The organization and administration of the Congress was increasingly handled by Indians. There is greater participation of scientists from the universities which was earlier restricted to the government officials from various scientific services. The general and sectional presidents of ISCA belonged to varied professions including, industrialists, university professors, those employed in scientific services, government departments, political leaders, etc. (ISCA Proceedings, 1914-1947). The increase in ISCA's membership from 60 in 1914 to 2500 in 1947 , is a clear indicator of professionalization (ASB, 1914; ISCA, 1947). However, its membership is highly skewed in nature (ISCA, 1948). Anderson hinted that scientists based in Bengal dominated Indian Science Congress (ISC) in 1930s and reiterated need to regulate its membership and demonstrate recognition for superior performance (Anderson, 2010, pp. 62-63).

\subsection{Platform for Scientists to Meet and Discuss}

ISCA annual sessions acted as a significant platform for catalyzing 'community' consciousness and integrated the scattered specialist groups on a national scale (Krishna et. al. 1997, p. 243). Although there is diversity in venues for its annual sessions. However, until independence the annual meetings of ISCA remained restricted to cities already identified as important centres for scientific learning and research along with few lesser emerging ones. A number of research groups emerged around scientists associated with ISCA. The sectional 
meetings of ISCA provided a medium for greater interaction and cooperation between scientists of same discipline. They provided scope for collaborations and we see numerous papers which were co-authored by two or more Indians as well as by Indian and European scientific workers (ASB, 1916). Various scientific institutions or departments organized annual meetings and social gathering of their respective discipline during ISC which enabled greater personal intercourse between scientific workers of same field. The ISCA's delegates included scientific workers from research institutions, colleges, universities, GOI, Provincial and State government along with numerous commercial bodies from across the country (ISCA Proceedings, 1914-1947).

ISCA was a forum for communication and cooperation among scientists of different fields. Numerous 'science dinners', 'science conversazione', etc. were organised, which effected greater personal and social intercourse between scientific workers (ISCA Proceedings, 19141947). In 1938, ten joint discussions concerning more than one section of the congress were held. In addition to BAAS delegates, a number of eminent scientists from international scientific institutions, academic bodies and universities attended the Congress in 1938 (ISCA, 1938). It became the largest and most representative organization of scientific workers in India. ISCA acted as a unique forum which enabled the young emerging scientists to interact with noted scientists. The presence of notable names among the General Presidents, Sectional Presidents validates its position as a viable association. ISCA became the national platform for showcasing advancement in varied scientific fields. It certainly provided a medium in order to impress upon the needs of the scientific community to the government. Most importantly, ISCA enabled greater recognition of social obligation of science in utilizing science for general welfare of the country with regard to food security, nutrition, health, diseases, population, agriculture, planning, etc. As a result, in 1939 at Lahore session of ISCA, a sub-committee of science and its social relations was set up (ISCA, 1939). ISCA certainly provided a platform for shaping and strengthening the scientific community.

\subsection{Knowledge Production in Different S\&T Fields}

Many scientists associated with ISCA have contributed immensely to knowledge production within their field of science. The proliferation of papers presented and numerous sections and subsection within ISCA annual sessions, is also a great indicator. At the first session of ISCA held at Calcutta, a total number of thirty-five papers were presented under six sections (ASB, 1914). It increased to 775 papers under fourteen sections at the Congress in 1941 (ISCA, 1941). The President of the seventeenth Congress stated that the congress provided most important stimulus to scientific research in the country (ISCA, 1930). ISCA became a national platform for showcasing scientific productivity and knowledge production. By the time of independence, although the scientific community of India was small as compared to other countries but it was wellorganized in fields like physics, chemistry, mathematics, medicine, geology and biological sciences (Krishna et al., 1997, p. 224). Many scientists associated with ISCA like J C Bose, P C Ray, C V Raman, Meghnad Saha, etc. played critical role in advancing pure science ${ }^{2}$ and have published numerous papers in international journals and were recognized internationally.

\footnotetext{
2 P C Ray discovered mercurous nitrite and published numerous papers in scientific journals. The output of research was increasing and there were growing instances of Indian scientific workers presenting their research at international platforms. $\mathrm{J} C$ Bose's research on electromagnetism was widely acclaimed. C V Raman did a ground-breaking research in physics and 'Raman Effect' was internationally recognized. M N Saha's formulation of theory of Thermal Ionization opened a new horizon in the field of astro-physics.
} 


\subsection{Peer Evaluation Systems and International Recognition}

ISCA sectional meetings provided the first instance of peer-evaluation system. The papers were reviewed and selected by sectional committee headed by the sectional president. The election as General and Sectional Presidents of ISCA was considered as a mark of fame. Anderson pointed out that Saha's reputation rose after he was elected as the President of the Physics Sections of ISC in 1925 (Anderson, 2010, p. 44). We see a marked increase in recognition of Indian scientific community both nationally and internationally. The presence of delegates from international societies and associations of science is a clear indicative of ISCA's fame during the period of study. A number of Indian scientific workers were sent on delegations and conferences abroad. They became fellows of international societies like the Royal Society of London and also received international awards which was a mark of great honour for Indian scientific community $^{3}$. ISCA enabled transformation of almost non-existent community consciousness of the Indian scientific workers into a viable scientific community.

\section{Conclusion}

ISCA certainly is a significant actor in shaping science in India during 1914 and 1947. The period witnessed growth of scientific departments, courses, university chairs, specialized institutes and laboratories. It saw greater participation and importance of universities in scientific research. ISCA's contribution was indispensable in the growth of scientific and learned societies, academies and associations of science as well as scientific journals. It provided an eco-system for the foundation and flourishing of numerous scientific institutions. ISCA's membership and greater participation of Indians in its annual sessions attests to it being a premier association which catered to numerous specialisms of science and showcased their advances. It stands testimony to the increasing scientific productivity of the Indian scientific community which began to be increasingly nationally and internationally recognized. It provided a forum for realization of peer-review and greater intra- and inter-discipline coordination and co-operation for solving various problem facing India. ISCA provided a research eco-system and a forum for greater realization of importance of science and scientists especially when India was entering a phase of self-rule and planning and development lie at the core of nationbuilding process. Although, Nehru was greatly involved with the activities of ISCA, there is a complete absence of Gandhi in the proceedings of ISCA.

\section{ACKNOWLedGements}

I am thankful to INSA and IJHS for publishing the proceedings of the conference 'Emergence of Modern Science in Colonial India', which gave an opportunity to young scholars to share the platform with stalwarts of history of science. This paper is a part of my Ph.D. research and I am extremely thankful to my supervisors, Prof. V V Krishna and Prof. Madhav Govind for their constant guidance and support. I specially thank the editorial team of IJHS along with Madhvendra Narayan for their untiring efforts. I also thank archives and libraries like National Archives of India, NISCAIR Library, Jawaharlal Nehru University, in New Delhi and ISCA HeadOffice and Asiatic Society of Bengal in Calcutta.

\footnotetext{
3 In 1920, J C Bose became the Fellow of the Royal Society of London followed by C V Raman in 1924. Raman was awarded the Matteucci Medal by the 'Societa Italiana Della Scienza' of Rome in 1928. In 1930, Raman was awarded the Nobel Prize in Physics for his work on scattering of light and for discovery of the 'Raman effect'. M N Saha was elected as FRS in 1928 and was also invited to the Volta centenary celebrations. in 1945, P C Mahalanobis was elected as the fellow of the Royal Society, London in 1946 and in the following year he was appointed a member of the Statistical Commission of the United Nations. S N Bose became FRS in 1958. The foreign societies conferred the Back award and Lyell Medal on D N Wadia.
} 


\section{BIBLIOGRAPHY}

Anderson, Robert S. Nucleus and Nation, Scientists, International Networks and Power in India, The University of Chicago, Chicago, 2010.

Baber, Z. The Science of Empire: Scientific Knowledge, Civilization and Colonial Rule in India, Oxford University Press, New Delhi: 1998.

Brojendra Lal Doss, Asiatic Society of Bengal, Asiatick Researches, Vol. I M.DCC.LXXXVIII, Calcutta.

Centenary Review of the Asiatic Society of Bengal from 1784 to 1883, Asiatic Society of Bengal, Calcutta: 1885.

Chakraborti, Pratik, Western Science in Modern India: Metropolitan Methods, Colonial Practices, Permanent Black, Delhi: 2004.

Gaillard, J; Krishna, V V and Waast, R. (eds.) Scientific Communities in the Developing World, Sage Publication, New Delhi, 1997

Home, Public, no. 49, 11 May 1826 and no. 91, 20 February 1784, National Archives of India, New Delhi

Home, Education, no. 57-58, August 1899, National Archives of India, New Delhi.

Howarth, O J R. The British Association for the Advancement of Science: A Retrospect, 1831-1931, British Association for the Advancement of Science, London, 1931.

Indian Association for the Cultivation of Science, A Century, Indian Association for the Cultivation of Science, Calcutta, 1976.

Indian Science Congress Association, Proceedings of the Seventeenth, Twentieth \& Twenty-First Indian Science Congress, Third Circuit, ISCA, Calcutta, 1930, 1933 \& 1934.

Indian Science Congress Association, Proceedings of the Twenty-Fifth Indian Science Congress, Part IV, ISCA, Calcutta, 1938.

Indian Science Congress Association, Proceedings of the Twenty-Seventh \& Thirty-Third Indian Science Congress, Part I, ISCA, Calcutta, 1940 \&1946.
Indian Science Congress Association, The Shaping of Indian Science - Indian Science Congress Association Presidential Addresses, Volume I: 1914-1947, Universities Press, Hyderabad: 2003.

Kolhstedt, S G. The formation of American scientific community: the American Association for the Advancement of Science, 1848-1860, University of Illinois, Chicago: 1976.

Krishna, V V. S S Bhatnagar on Science, Technology and Development, 1938-1954, Wiley Eastern Limited, New Delhi: 1993.

Kumar, D. Science and the Raj, A Study of British India, Second Edition, Oxford University Press, New Delhi: 2006.

Kumar, D (ed.). Science and Empire: Essays in Indian Context - 1700-1947, Anamika Prakashan, Delhi, 1991.

MacLeod, Roy (ed.). The Commonwealth of Science: ANZAAS and the Scientific Enterprise in Australasia, 1888-1988, Oxford University Press, Australia: 1988.

Proceedings of the Asiatic Society of Bengal, Calcutta, 1829.

Proceedings of National Institute of Sciences of India, NISI, Calcutta: 1935.

Raina, D and Habib, S Irfan. Domesticating Modern Science: A Social History of Science and Culture in Colonial India, Tulika Books, New Delhi, 2004.

Raj, Kapil. Relocating Modern Science, Circulation and Construction of Knoweldge in South Asia and Europe, 1650-1900, Palgrave Macmillan, New York, 2007.

Sangwan, S. Science, Technology and Colonialization: An Indian Experience 1757-1857, NISTADS- CSIR, New Delhi, 1991.

The First \& Third Indian Science Congress, Proceeding of the Asiatic Society of Bengal, Asiatic Society of Bengal, Calcutta, 1914 \& 1917.

The Seventh, Eleventh \& Thirteenth Indian Science Congress, Proceedings of the Asiatic Society of Bengal, N.S. XVI, XXI \& XXIV Calcutta, 1920, 1924 \& 1926. 